\title{
ARMAZENAMENTO E GERMINAÇÃO DE SEMENTES DE UVAIA Eugenia uvalha Cambess
}

\author{
Storage and germination of Eugenia uvalha Cambess seeds
}

\author{
Silvana de Paula Quintão Scalon ${ }^{1}$, Homero Scalon Filho ${ }^{1}$, Marilúcia Rossi Rigoni ${ }^{2}$
}

\begin{abstract}
RESUMO
Com o presente trabalho, objetivou-se testar o tempo e temperatura de armazenagem e tratamentos pré-germinativos na germinação de sementes de uvaia (Eugenia uvalha Cambess). As sementes foram separadas em lotes de 100 unidades, que foram pesadas e, em seguida, armazenadas em temperatura ambiente $\left(30 \pm 2^{\circ} \mathrm{C}\right)$ e em geladeira $\left(13 \pm 2^{\circ} \mathrm{C}\right)$, sendo acondicionadas em frascos de plástico com tampa rosqueada. No início do experimento e a cada 30 dias (30, 60, 90 e 120 dias de armazenamento), as sementes foram imersas por 30 minutos em água quente ou GA 125 mg. $\mathrm{L}^{-1}$ e GA $250 \mathrm{mg}$. L $\mathrm{L}^{-1}$ por doze horas, e aquelas sem nenhum tratamento serviram como testemunha; em seguida, foram semeadas em recipiente contendo terra + areia (1:1) como substrato. Foram avaliados a percentagem de emergência e o índice de velocidade de emergência. O experimento foi conduzido em esquema fatorial 2 (temperaturas de armazenamento) x 4 (tratamentos pré-germinativos) x 4 (períodos de armazenamento) em delineamento inteiramente casualizado com quatro repetições de 25 sementes. As sementes armazenadas em refrigeração apresentaram, em geral, maior percentagem e índice de velocidade de emergência. As sementes de uvaia recém-colhidas não emergiram até os 200 dias de observação. Sob armazenamento à temperatura ambiente, houve menor emergência (32,14\%) que aquelas sob refrigeração (40,37\%). Quanto aos períodos de armazenamento, a maior emergência foi observada nas sementes armazenadas por 60 dias sob refrigeração (65,56\%) e 90 dias sob temperatura ambiente (52,03\%). GA 125 mg. $\mathrm{L}^{-1}$, sob refrigeração, e GA $250 \mathrm{mg} . \mathrm{L}^{-1}$, sob temperatura ambiente, foram os tratamentos pré-germinativos com maior emergência. O índice de velocidade de emergência foi maior nas sementes armazenadas sob refrigeração, e aos 60 dias (0,099), esse índice foi maior, comparado com as sementes por 90 dias $(0,069)$ sob temperatura ambiente. As sementes imersas em giberelina alcançaram o maior IVE (acima de 0,05).
\end{abstract}

Termos para indexação: Uvalha, Myrtaceae, emergência, Eugenia uvalha.

\section{ABSTRACT}

This work has as objective to test storage time and temperature and pre germinative treatments on germination of Eugenia uvalha Cambess. Seeds were separated in lots of 100 units, which were weighted and follow they were stored in environment temperature $\left(30 \pm 2^{\circ} \mathrm{C}\right)$ and in the refrigerator at $13 \pm 2^{\circ} \mathrm{C}$ inside plastic bottles with spiral lid. At the beginning of the experiment and at 30 days (30, 60, 90 and 120 days of storage) seeds were immersed for 30 minutes in hot water, GA 125 mg.L $L^{-1}$ and GA 250 mg.L $L^{-1}$ or control, and follow they were sowed in container which contained soil and sand (1:1) as substratum. Emergence percentage and emergence velocity index were evaluated. Experiment was carried out in a 2 (storage temperature) x 4 (storage periods) factorial scheme in a complete randomized block design with four replications of 25 seeds. Seeds stored under refrigeration showed in general higher percentage and emergence velocity index. Eugenia uvalha Cambess seeds recently gathered did not emerge until the end of 200 days of observation. Under environment temperature there was smaller emergence (32.14\%) than those under refrigeration (40.37\%). Regarding storage periods, the highest emergence was observed in seeds stored by 60 days under refrigeration (65.56\%) and 90 days under environment temperature (52.03\%). GA 125 mg. $\mathrm{L}^{-1}$ under refrigeration and GA 250mg.L ${ }^{-1}$ under environment temperature were pregerminative treatments with the highest emergence. Emergence velocity index was higher in seeds stored under refrigeration, and at 60 days (0.099) that index was higher compared with seeds stored by 90 days (0.069) under environment temperature. Regarding to pregerminative treatments, seeds immersed in gibereline reached the highest emergence velocity index (above 0.05 ).

Index-terms: Eugenia uvalha, Myrtaceae, emergence.

(Recebido para publicação em 11 de setembro de 2003 e aprovado em 27 de setembro de 2004)

\section{INTRODUÇÃO}

A Eugenia uvalha (Myrtaceae), popularmente conhecida como uvalheira, uvalha ou uvaia é uma árvore de seis a treze metros de altura, dotada de copa arredondada, tronco geralmente ereto, com 30 a 50 centímetros de diâmetro, a madeira dura, pesada, resistente, sendo empregada apenas localmente para mourões, estacas, postes e para lenha e carvão. Possui flores solitárias, de cor branca e floresce no mês de agosto a setembro, com início de maturação dos frutos 
em setembro, prolongando-se até novembro. Os frutos, drupas globosas de cor amarela, são deiscentes, carnosos, contendo de uma a três sementes que apresentam tegumento de coloração castanha, cotilédones carnosos e justapostos. Após a extração, as sementes oxidam-se rapidamente, provocando um escurecimento nos cotilédones, que se inicia na periferia, indo em direção à parte central da semente. O fruto é comestível, sendo muito apreciado na forma de sucos. Também é muito procurado por várias espécies de pássaros, o que o torna bastante recomendável para reflorestamentos heterogêneos destinados à recomposição da vegetação de áreas degradadas de preservação permanente (LORENZI, 1998; ANDRADE e FERREIRA, 2000).

Como a maioria das espécies frutíferas silvestres brasileiras não é comercializada extensivamente, informações básicas sobre a propagação, cultivo e potencialidade dessas espécies, visando à sua utilização na arborização urbana, sua manutenção em bancos de germoplasma, e inclusive sua perpetuação, tornam-se necessárias. Um outro aspecto relevante é o fato de que, nas Regras para Análise de Sementes (BRASIL, 1992), são poucas as prescrições e/ou recomendações básicas sobre os métodos e técnicas adequadas a serem empregas nas análises de sementes de espécies frutíferas silvestres, diante da grande diversidade da flora nacional (BARBOSA et al., 1990).

Como para muitas espécies não é possível proceder à semeadura logo após a colheita, as sementes devem ser armazenadas. Condições de baixa temperatura e umidade são recomendadas para armazenar a maioria das sementes (VERTUCCI e ROOS, 1993), embora algumas espécies apresentem exigências diferentes. As condições de armazenamento irão interferir no período máximo desse armazenamento e na germinação final das sementes, podendo até levar a semente a algum tipo de dormência secundária.

Alguns pesquisadores consideram que a semeadura da uvaia deve ocorrer logo após a colheita, uma vez que suas sementes apresentam baixa longevidade (MATTOS, 1956; REITZ et al., 1988, citados por ANDRADE e FERREIRA, 2000). Esses autores observaram 67\% de germinação de sementes recém-colhidas, comparando as condições de armazenamento após 30 dias sob câmara seca $\left(15 \pm 2^{\circ} \mathrm{C}\right.$ e $60 \%$ UR), e constataram redução de $91 \%$ na germinação comparada com a de $16 \%$ em câmara fria ( $5 \pm 2^{\circ} \mathrm{C}$ e $90 \%$ UR). Durante 60 dias, as condições da câmara fria mantiveram o grau de umidade das sementes em níveis superiores a $20 \%$ e a porcentagem de emergência acima de 50\%; em condições de câmara seca, o grau de umidade foi reduzido em níveis inferiores a $20 \%$ aos
30 dias de armazenamento, conduzindo as sementes à perda total da germinação aos 45 dias, quando o grau de umidade atingiu valores de $14 \%$, apresentando, assim, comportamento recalcitrante.

Estudando a germinação de sementes de uvalha, Barbosa et al. (1990) observaram que não houve diferença significativa na porcentagem de germinação quando as sementes foram semeadas nos substratos sobre papel, entre areia ou terra, em que foram alcançados valores de 34 a 40.5\%. Maiores valores de germinação foram observados a $30^{\circ} \mathrm{C}(59.11 \%)$, quando comparados aos verificados sob 20 e $25^{\circ} \mathrm{C}$ (média de $36 \%$ ).

$\mathrm{O}$ tamanho da semente pode interferir no processo da germinação - sementes pequenas $(0,2$ a $0,5 g)$ e grandes (0,9 a 2,0g) apresentam 35 - 38\% de germinação, quando comparadas com $53 \%$ das sementes médias $(0,5$ a $0,9 g)$ e tempo médio para germinar de $60-70$ dias. $O$ processo de germinação é lento e desuniforme, estendendo-se até 135 dias (ANDRADE e FERREIRA, 2000).

$\mathrm{O}$ uso de reguladores de crescimento que estimulem a germinação de sementes de algumas espécies vegetais nativas é importante e, nesse contexto, o uso da giberelina tem sido fundamental, pois está relacionado com a síntese de enzimas hidrolíticas que degradam reservas como amido e proteínas, as quais são usadas no desenvolvimento do embrião e também no alongamento da radícula. O baixo índice de germinação e a heterogeneidade das plântulas emergidas podem ser resultado do balanço entre promotores e inibidores de crescimento. Assim, pode ser empregado o uso de ácido giberélico na promoção da germinação, pois esse, entre outros fatores, promove aumento do alongamento celular (TAIZ e ZEIGER, 1991; SALISBURY e ROSS, 1992; FERREIRA et al., 2001).

O presente trabalho foi realizado com o objetivo de testar a temperatura e o tempo de armazenagem e tratamentos pré-germinativos na germinação de sementes de uvaia (Eugenia uvalha Cambess).

\section{MATERIAL E MÉTODOS}

Os frutos de uvaias (Eugenia uvalha) foram colhidos em Dourados-MS, no dia 27 de outubro de 2000, em uma única árvore, sendo selecionados quanto à maturidade (coloração amarelo-ouro) e sanidade (sem sinais de ataque por microrganismo). Após a colheita, os frutos foram levados para o laboratório de botânica da UNIGRAN, onde se procedeu à extração e lavagem manual das sementes em água corrente. As sementes foram selecionadas segundo o tamanho $(0,6-1,0 \mathrm{~g})$, separadas em lotes de 100 unidades e acondicionadas em frascos de plástico com tampa rosqueada; em seguida, 
foram armazenadas em temperatura ambiente (30 \pm $\left.2^{\circ} \mathrm{C}\right)$ e em geladeira a $\left(13 \pm 2{ }^{\circ} \mathrm{C}\right)$. No início do experimento e a cada 30 dias (30, 60, 90 e 120 dias de armazenamento), as sementes foram imersas por 30 minutos em água quente (em banho-maria a $70^{\circ} \mathrm{C} \pm 2^{\circ} \mathrm{C}$ ); solução de GA 125 mg.L. ${ }^{-1}$ e GA 250 mg.L ${ }^{-1}$ por doze horas e, aquelas que não receberam nenhum tratamento, serviram como testemunha. A semeadura ocorreu em recipiente plástico $(12 \times 8 \mathrm{~cm})$ contendo terra + areia $(1: 1)$ como substrato. Após a semeadura, os recipientes foram mantidos em casa-de-vegetação à temperatura de $32^{\circ} \mathrm{C}$ $\pm 2^{\circ} \mathrm{C}$. O controle da emergência do epicótilo foi realizado a cada dois dias, anotando-se o número de plântulas normais emergidas para fins de cálculo da porcentagem de emergência e índice de velocidade de emergência, segundo Popinigis (1985).

O experimento foi conduzido em esquema fatorial com duas temperaturas de armazenamento x quatro tratamentos pré-germinativos x quatro períodos de armazenamento em Delineamento Inteiramente Casualizado com quatro repetições de 25 sementes. Os resultados foram submetidos à análise de variância e as médias, comparadas pelo teste de Duncan a $1 \%$ de probabilidade.

\section{RESULTADO E DISCUSSÃO}

As sementes de uvaia recém-colhidas (0 dias de armazenamento) não germinaram até os 200 dias de observação. Esses resultados contrariam aqueles observados por Andrade e Ferreira (2000), que observaram emer-

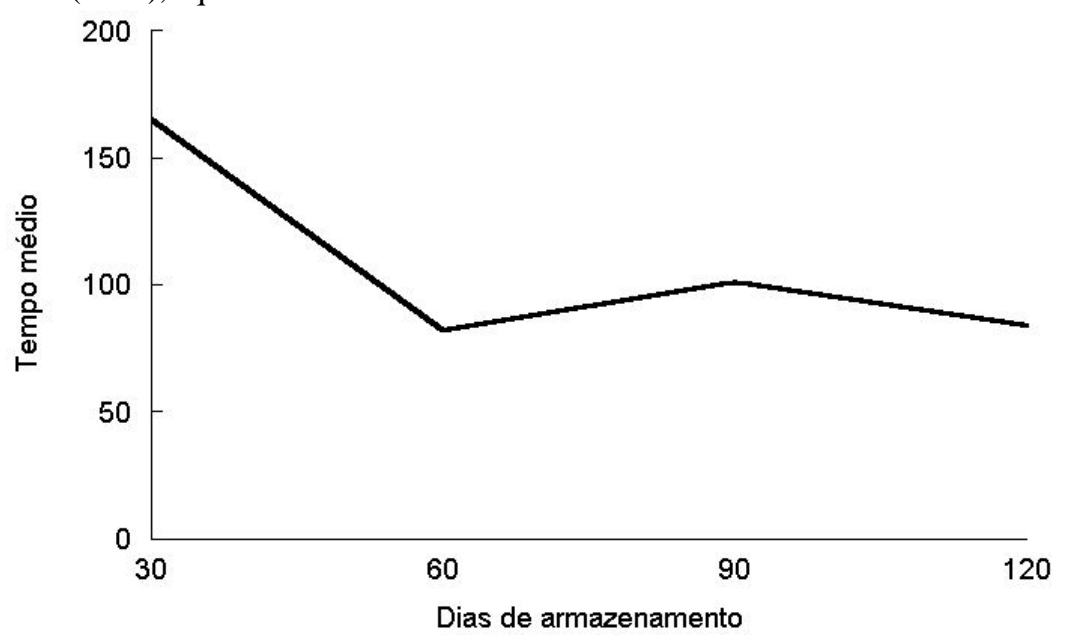

Dias de armazenamento gência de 67\%. Provavelmente, o grau de maturidade fisiológica das sementes nesses dois trabalhos tenha sido diferente. O tempo médio de emergência das plântulas provenientes de sementes armazenadas reduziu-se com o aumento do período de armazenamento. As sementes armazenadas durante 30 e 120 dias germinaram aos 168 e 65 dias, respectivamente (Figura 1).

As sementes armazenadas sob refrigeração apresentaram maior germinação e IVE aos 60 dias (65,56\% e 0,099, respectivamente), sendo o melhor tratamento pré-germinativo a imersão em GA $125 \mathrm{mg} \mathrm{L}^{-1}$ (52,07\% e 0,073$)$. Sob temperatura ambiente, a maior germinação e IVE foram observados aos 90 dias (52,03\% e 0,062), sendo o melhor tratamento pré-germinativo a imersão em GA $250 \mathrm{mg} \mathrm{L}^{-1}(39,80)$, embora para a temperatura ambiente o IVE não tenha variado entre os tratamentos de GA (média de 0,044) (Tabela 1).

Os resultados encontrados no presente trabalho também podem ser indicativos de que as sementes poderiam estar ainda imaturas e com baixos níveis de giberelina endógena, uma vez que, até aos 60 dias de armazenamento refrigerado, as sementes só emergiram quando receberam tratamentos com giberelina ou água quente (Figura 2b). Andrade e Ferreira (2000) consideram que o longo período necessário para as sementes de uvaia germinarem seja devido ao fato de elas possuírem embrião globoso, sem diferenciação dos cotilédones nem do eixo hipocótilo-radícula e alto nível de compostos fenólicos, os quais “seqüestram” o oxigênio necessário ao processo respiratório (PINOL e PALAZÓN, 1993).

FIGURA 1 - Tempo médio para emergência de sementes de uvaia armazenadas durante 30, 60, 90 e 120 dias. Dourados, MS. 2001. 
TABELA 1 - Porcentagem de emergência e Índice de velocidade de emergência de sementes de uvaia (Eugenia uvallha).

\begin{tabular}{|c|c|c|c|c|}
\hline & \multicolumn{2}{|c|}{ Emergência (\%) } & \multicolumn{2}{|c|}{ IVE } \\
\hline & Refrigeração & Ambiente & Refrigeração & Ambiente \\
\hline \multicolumn{5}{|c|}{ Dias de Armazenamento } \\
\hline 30 & 8.42 & 18.90 Ad & $0.006 \mathrm{Bd}$ & $0.018 \mathrm{Ad}$ \\
\hline 60 & 65.56 Аа & $33.46 \mathrm{Bb}$ & 0.099 Аа & $0.033 \mathrm{Bb}$ \\
\hline 90 & $58.56 \mathrm{Ab}$ & 52.03 Аа & $0.069 \mathrm{Ab}$ & $0.062 \mathrm{Aa}$ \\
\hline 120 & $29.13 \mathrm{Bc}$ & 31.33 Ac & 0.042 Ac & $0.024 \mathrm{Bc}$ \\
\hline \multicolumn{5}{|c|}{ Tratamentos Pré-Germinativos } \\
\hline GA 250 & $49.99 \mathrm{Ab}$ & $39.80 \mathrm{Ba}$ & $0.063 \mathrm{Ab}$ & $0.042 \mathrm{Ba}$ \\
\hline GA 125 & 52.07 Аа & $35.38 \mathrm{Bb}$ & 0.073 Аа & $0.046 \mathrm{Ba}$ \\
\hline Testemunha & 36.53 Ac & $35.41 \mathrm{Ab}$ & 0.048 Ac & $0.038 \mathrm{Bb}$ \\
\hline Agua quente & $22.90 \mathrm{Ad}$ & $10.51 \mathrm{Bc}$ & $0.031 \mathrm{Ad}$ & $0.011 \mathrm{Bc}$ \\
\hline
\end{tabular}

Médias seguidas de mesma letra maiúscula na linha e minúscula na coluna não diferem entre si pelo teste de Duncan a $1 \%$ de probabilidade.

Menores valores de emergência em plântulas foram observados em sementes armazenadas por 30 dias, tanto sob temperatura ambiente quanto sob refrigeração (Figura 2a e b). Aos 60 e 90 dias sob temperatura ambiente e refrigeração, a maior emergência foi observada em sementes tratadas com giberelina, embora aos 90 dias sob refrigeração, o tratamento com GA 125 não tenha variado significativamente da testemunha, alcançando valores de 91,6\% , sendo esse o valor máximo de emergência obtido no experimento.

Aos 120 dias, a porcentagem de emergência se reduziu, porém, manteve valores superiores a 50\% quando armazenadas sob refrigeração; sob temperatura ambiente, a maior emergência foi observada nas sementes que serviram de testemunha; já sob refrigeração, não houve diferença entre as sementes testemunhas e tratadas com GA 250.

A imersão em água quente foi prejudicial às sementes e pode ter danificado ou induzido algum tipo de dormência no embrião das sementes após 60 dias de armazenamento, uma vez que não foi observada nenhuma emergência tanto sob temperatura ambiente quanto refrigerada. Andrade e Ferreira (2000), em sua revisão, observaram que a imersão em água quente pode causar lixiviação de parte dos constituintes celulares da semente ou, segundo Popinigis (1985), redução da disponibilidade de oxigênio em condição de temperatura elevada $\left(28^{\circ} \mathrm{C}\right)$ durante a embebição das sementes. Este autor observou que a reidratação das macromoléculas e organelas celulares aumenta as atividades respiratórias das sementes e, portanto, aumenta o requerimento de oxigênio.

O índice de velocidade de emergência foi maior nas sementes sob refrigeração e apresentou o mesmo comportamento da porcentagem de emergência para dias de armazenamento; entretanto, para tratamentos prégerminativos, observa-se que o maior IVE foi alcançado em sementes tratadas com GA 125. Sob refrigeração aos 60 dias, o IVE foi maior, comparado com o observado em sementes armazenadas por 90 dias sob temperatura ambiente (Tabela 1 e Figura 3a e b).

As sementes germinaram lentamente, resultando em baixos índice de velocidade de emergência das plântulas. Andrade e Ferreira (2000) observaram que em condições controladas de laboratório, a germinação de sementes de uvaia não ocorreu antes de 30 dias, mesmo quando o grau de umidade das sementes e a temperatura do ambiente foram semelhantes àquelas observadas no seu habitat natural, devendo apresentar um mecanismo de dormência. 
a)

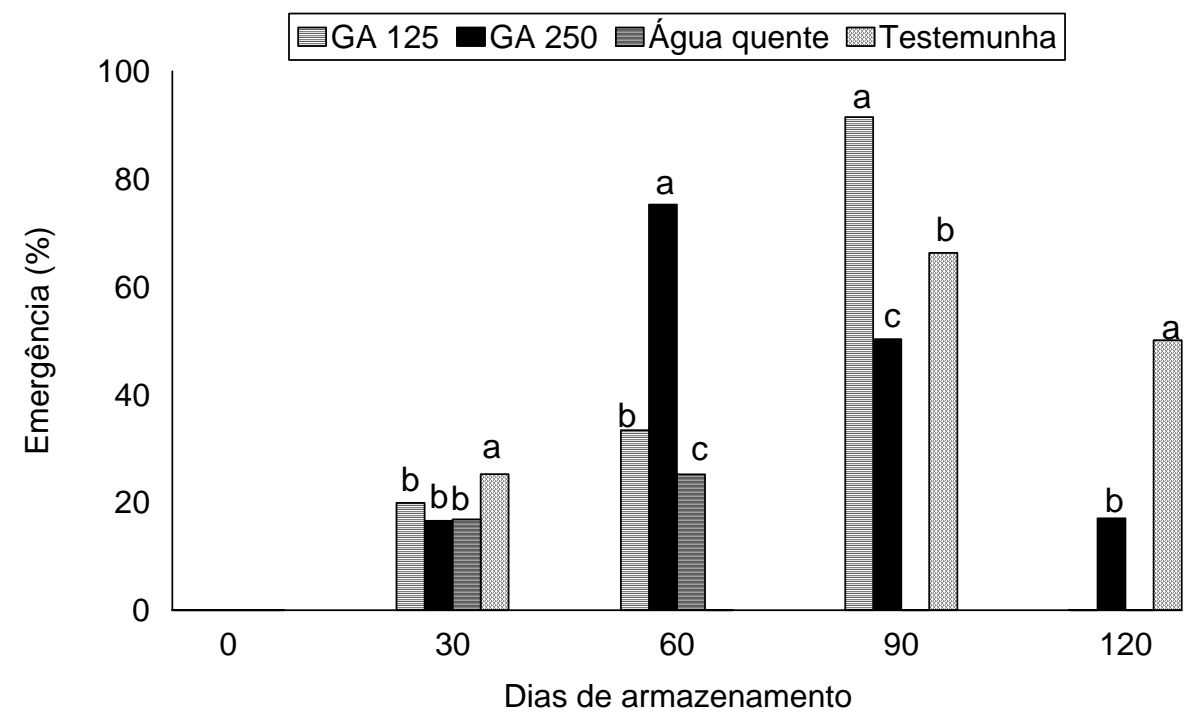

b)

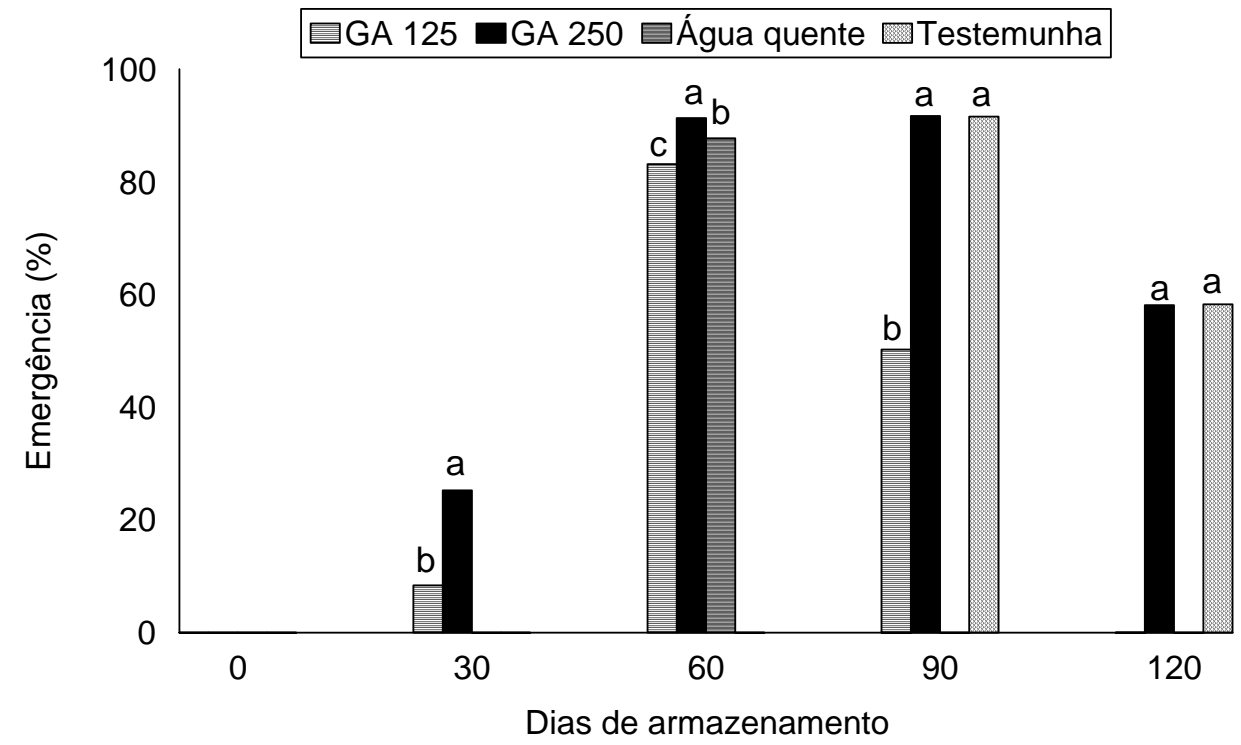

FIGURA 2 - Emergência de sementes de uvaia (Eugenia uvallha) armazenadas sob temperatura ambiente (a) ou refrigeração (b). 
a)

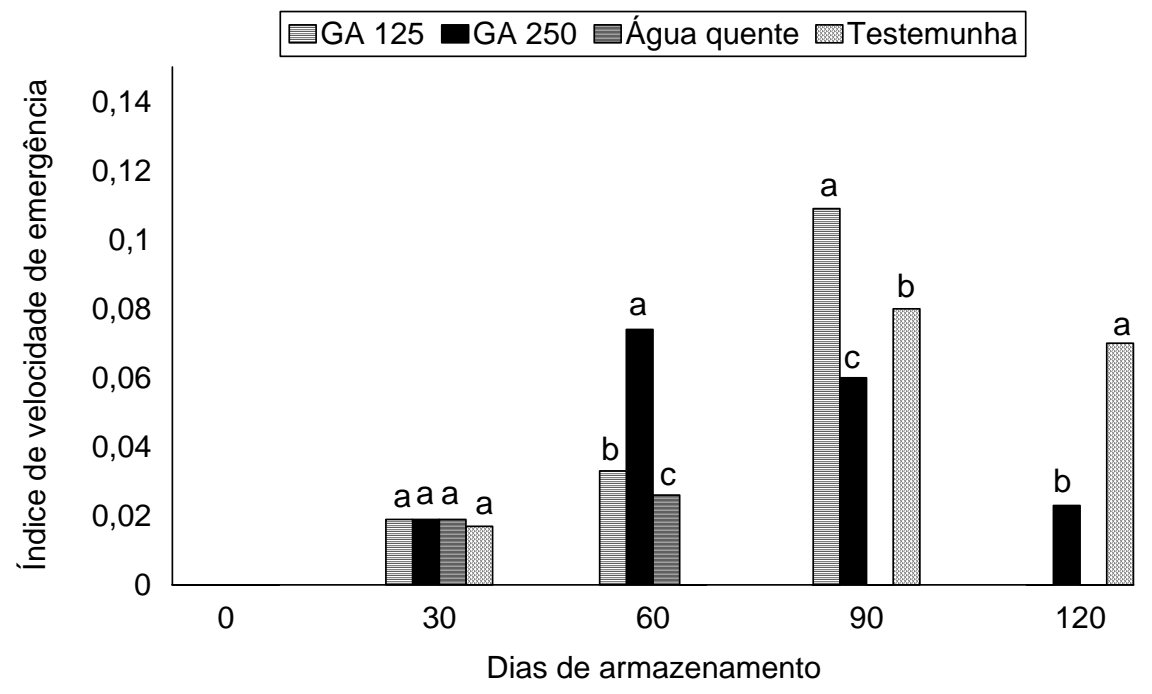

b)

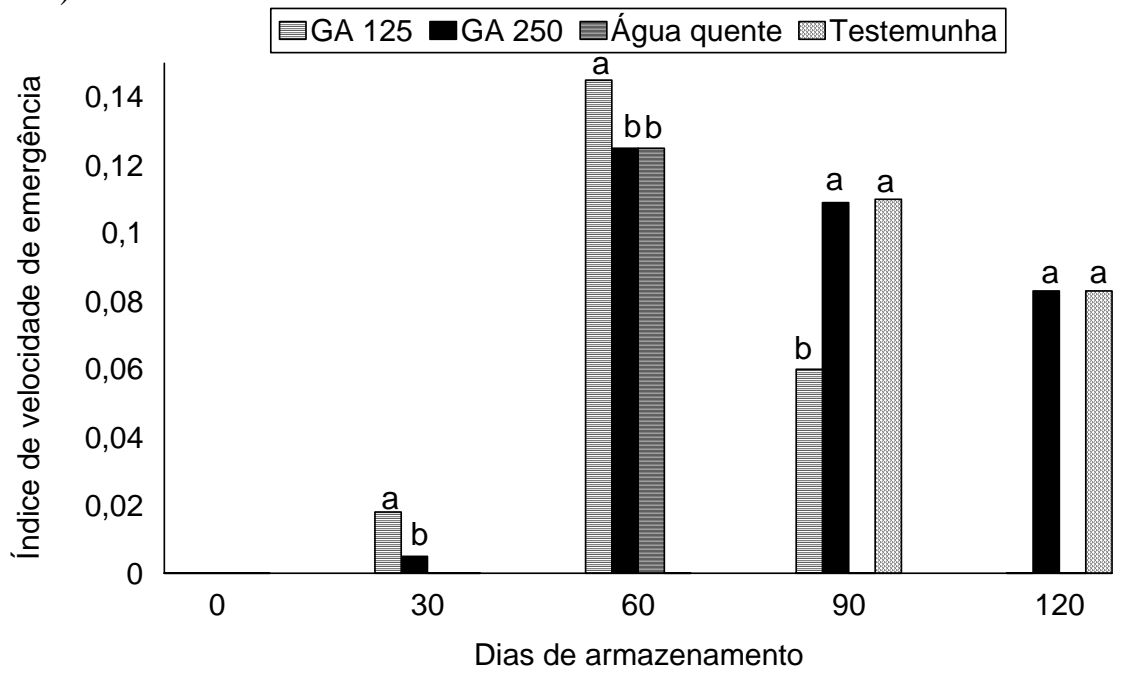

FIGURA 3 - Índice de velocidade de emergência de sementes de uvaia (Eugenia uvallha) armazenadas sob temperatura ambiente (a) ou refrigeração (b).

\section{CONCLUSÃO}

Baseado nos resultados obtidos, pode-se concluir que as sementes de uvaia não devem ser semeadas logo após sua retirada dos frutos e não devem ser tratadas com água quente. O tratamento com giberelina estimula a germinação de sementes armazenadas por 60 dias. As sementes podem ser armazenadas por 90 dias sob refrigeração, sem necessitar de tratamento prégerminativo.

\section{REFERÊNCIAS BIBLIOGRÁFICAS}

ANDRADE, R. N. B.; FERREIRA, A. G. Germinação e armazenamento de sementes de uvaia (Eugenia pyriformis Camb.) - Myrtaceae. Revista Brasileira de Sementes, Brasília, v. 22, n. 2, p. 118-125, 2000.

BARBOSA, J. M. et al. Influência de substratos e temperatura na germinação de sementes de duas frutíferas silvestres. Revista Brasileira de Sementes, Brasília, ano 12, n. 2, p. 66-73, 1990. 
BRASIL. Ministério da Agricultura e Reforma Agrária. Regras para análise e sementes. Brasília: SNDA/DNDV/CLAV, 1992. 365 p.

FERREIRA, G.; SEIDEL, G. O.; VERONA, M. M. Efeito de fitorregladores na germinação de sementes de atemóia (Annona cherimola Mill. X Annona squamosa L.). In: CONGRESSO NACIONAL DE FISIOLOGIA VEGETAL, 8., 2001, Ilhéus. Resumos... Ilhéus: [s.n.], 2001. CDROM.

LORENZI, H. Árvores brasileiras: manual de identificação e cultivo de plantas arbóreas nativas do Brasil. Nova Odessa: Plantarum, 1998. 352 p.
PINOL, M. T.; PALAZÓN, J. Fisiología y bioquímica vegetal. Madrid: McGraw Hill, 1993. 581 p.

POPINIGS , F. Fisiologia de sementes. Brasília: Agriplan, 1985. 285 p.

SALISBURY, F. B.; ROSS, C. W. Plant phisiology. 4. ed. Califórnia: Wadsworth, 1992. 682 p.

TAÍZ, L.; ZEIGER, E. Plant phisiology. California: The Benjamin Cummings, 1991. 559 p.

VERTUCCI, C. W.; ROSS, E. E. Seed storage, temperature and relative humidity: response. Seeds Science Research, Kew, v. 3, n. 3, p. 215-216, 1993. 